\title{
Heavy Metal Toxicity in Aba River Abia State Nigeria
}

\author{
N.M. Mgbemena \\ Department of chemistry Micheal Okpara University of Agiculture Umudike
}

\begin{abstract}
The growing menace of heavy metals in Aba River is of a major concern. The contamination by heavy metals arise from the various discharges into the River. Aba River was divided into three streams; the upstream, midstream and downstream and analyzed for the presence of 12 heavy metals both in the dry and rainy season. Three composite samples were collected from each stream and analyzed after digestion using atomic absorption spectrophotometer. The results showed the level of heavy metals in Aba River as $\mathrm{Cr} 0.268 \pm$ $0.34 \mathrm{mg} / \mathrm{dm} 3, \quad P b \quad 0.489+0.11 \mathrm{mg} / \mathrm{dm}^{3}, \quad C u \quad 0.154 \pm 0.002 \mathrm{mg} / \mathrm{dm}^{3}, \quad C o \quad 0.192+0.040 \mathrm{mg} / \mathrm{dm}^{3}, \quad V \quad 0.141+$ $0.004 \mathrm{mg} / \mathrm{dm}^{3}, \mathrm{Fe} 8.701+0.48 \mathrm{mg} / \mathrm{dm}^{3}, \mathrm{Mn} 0.056+0.008 \mathrm{mg} / \mathrm{dm}^{3}, \mathrm{Cd} 0.491+0.003 \mathrm{mg} / \mathrm{dm}^{3}, \mathrm{Ni} 0.057 \pm 0.000 \mathrm{mg} / \mathrm{dm}^{3}$, Zn $0.092 \pm 0.001 \mathrm{mg} / \mathrm{dm}^{3}, \mathrm{Hg} 0.206 \pm 0.002 \mathrm{mg} / \mathrm{dm}^{3}$ and $\mathrm{As} 0.095 \pm 0 . \overline{00} 8 \mathrm{mg} / \mathrm{dm}^{3}$. These results were compared with standards of four regulatory bodies and some were found to be very high compared with the standards. The concentrations of most of the heavy metals were higher in the dry season and at the downstream. Urgent measures should therefore be taken to avoid a disastrous effect of these metals on man and other organisms using the water.
\end{abstract}

Keywords: Heavy metals, toxicity, concentration.

\section{Introduction}

Man's increased effort to better his living conditions have led to increase in the advances in technology, industrialization and subsequent urbanization. These advances in turn led to the increased production of a variety of goods and services that later turn to wastes, either as gaseous emissions, liquid effluents or solid wastes that get into our waters one way or the other.

Water bodies therefore become potential carriers of most toxic organic and inorganic materials, biodegradable and non- biodegradable matters, and pathogenic microbes that endanger animal and human life (1). Water contaminated with municipal sewage is the root cause of most dangerous diseases in living beings. Municipal waste arise from slums, refuse, residential areas, restaurants, hotel, animal excreta, farm products, human faucal matters and wooden materials etc. they inflict illness either through the direct consumption of contaminated water or through the food chain (1). Disease like typhoid, hepatitis, dysentery, cholera, skin disease, gastroenteritis are endemic in Nigeria and some parts of West Africa and are easily contacted through drinking of infected water. Water that contains toxic metals are harmful to fish planktons and insects that live in them. Industrial wastes have a wide variety of heavy metals and other toxic substances in them. Heavy metals contamination in water is mostly caused by wastewater arising from industrial effluents. Heavy metals like lead, mercury, cadmium, arsenic, barium etc contaminate water bodies like lakes, streams, rivers and the seas. These heavy metals in very low concentrations cause chronic poisoning which result in a wide variety of neurological and other diseases. Other historical causes of catastrophic and endemic exposures of heavy metals abound in literature. Minamata disease (2), the pink disease (3), the Bradford sweet poisoning $(4,5)$, the Itai-itai disease (6), Iraq mercury poisoning (7) and Alexander litvinenko poisoning (8) are all heavy metal associated calamities.

Heavy metals contamination affects the aquatic ecosystems sufficiently thereby altering the water quality, such spectacular cases of heavy metal poisoning have led Koli et al (9) to their statement that "By the end of this Century the waters of our world may be lifeless. Since the beginning of this Century, contaminating wastes dumped into our lakes, rivers and streams have increased more than $600 \%$. Fishes are dying". The seriousness of the situation has led to the work on Aba River since Aba is surrounded by a myriad of industries that empty their effluents into the River.

\section{Materials And Methods}

Aba River covers a distance of about 30 kilometers starting from Umuokpu to Ogbor Hill. The river was divided into three, the upstream, the midstream and the downstream. Four water samples were collected in each of the three delineated points. The four water samples from each point were thereafter mixed to obtain a composite sample. Three different composite samples were collected from each stream with plastic cups and empted into a $2 \mathrm{dm}^{3}$ plastic container. The sampling of the river was carried out in two seasons-the dry and the rainy seasons. The dry season samples were collected between February and March while the rainy season samples were collected between August and September. 
The heavy metals in the digested waters were analyzed using the Atomic Absorption Spectrometer, model 400, Pye Unicam (10) according to the prescriptions outlined by Adefemi et al 2007 (11).

\section{Results And Discussion}

Results Of The Levels Of Heavy Metal Concentration In Water Samples $\left(\mathrm{Mg} / \mathrm{Dm}^{3}\right)$ In The Dry Season In The Three Streams

Table 1: Dry Seasons

\begin{tabular}{lllll}
\hline Metals & Location & & \\
\hline & DSU & DSM & DSD & Average \\
Chromium & $0.604 \pm 000$ & $0.614 \pm 000$ & $0.810 \pm 000$ & $0.67 \pm 0.000$ \\
Lead & $0.620 \pm 0.000$ & $0.630 \pm 000$ & $0.650 \pm 0.005$ & $0.63 \overline{3} \pm 0.001$ \\
Copper & $0.340 \pm 0.000$ & $0.420 \pm 0.006$ & $0.017 \pm 0.001$ & $0.259 \pm 0.002$ \\
Cobalt & $0.057 \pm 1.53$ & $0.065 \pm 0.005$ & $0.70 \pm 0.000$ & $0.2714 \pm 0.512$ \\
Vanadium & $0.059 \pm 0.000$ & $0.059 \pm 0.005$ & $0.066 \pm 0.005$ & $0.061 \pm 0.003$ \\
Iron & $5.00 \pm 0.000$ & $5.40 \pm 0.000$ & $6.00 \pm 0.000$ & $5.46 \pm 0.000$ \\
Manganese & $0.025 \pm 0.000$ & $0.250 \pm 0.000$ & $0.021 \pm 0.001$ & $0.16 \overline{2} \pm 0.000$ \\
Cadmium & $0.065 \pm 0.000$ & $0.066 \pm 0.000$ & $0.073 \pm 0.003$ & $0.068 \pm 0.001$ \\
Nickel & $0.100 \pm 0.000$ & $0.050 \pm 0.000$ & $0.020 \pm 0.000$ & $0.056 \pm 0.000$ \\
Zinc & $0.066 \pm 0.000$ & $0.082 \pm 0.000$ & $0.86 \pm 0.000$ & $0.078 \pm 0.000$ \\
Mercury & $0.043 \pm 0.00$ & $0.065 \pm 0.00$ & $0.070 \pm 0005$ & $0.059 \pm 0.000$ \\
Arsenic & $0.006 \pm 0.00$ & $0.013 \pm 000$ & $0.550 \pm 0.050$ & $0.1897 \pm 0.166$
\end{tabular}

Legend:

DSU $=$ Dry Season Upstream

DSM $=$ Dry Season Midstream

DSD $=$ Dry Season Downstream

Results Of The Levels Of Heavy Metal Concentration In Water Samples $\left(\mathrm{Mg} / \mathrm{Dm}^{3}\right)$ In The Rainy Season In The Three Streams

Table 2: Rainy Season

Legend:

\begin{tabular}{lllll}
\hline Metals & Location & & & \\
& RSU & RSM & RSD & Average \\
\hline Chromium & $0.532 \pm 0.002$ & $0.590 \pm 007$ & $0.620 \pm 0.200$ & $0.580 \pm 0.070$ \\
Lead & $0.260 \pm 0.005$ & $0.37 \pm 0.013$ & $0.406 \pm 0.000$ & $0.345 \pm 0.006$ \\
Copper & $0.071 \pm 0.005$ & $0.042 \pm 0.002$ & $0.087 \pm 0.000$ & $0.049 \pm 0.002$ \\
Cobalt & $0.250 \pm 0.005$ & $0.042 \pm 0.002$ & $0.035 \pm 0.000$ & $0.109 \pm 0.002$ \\
Vanadium & $0.200 \pm 0.000$ & $0.210 \pm 0.000$ & $0.234 \pm 0.001$ & $0.215 \pm 0.000$ \\
Iron & $12.04 \pm 0.04$ & $10.60 \pm 0.170$ & $13.20 \pm 0.075$ & $11.95 \pm 0.095$ \\
Manganese & $0.017 \pm 0.005$ & $0.002 \pm 0.000$ & $0.018 \pm 0.00$ & $0123 \pm 0.001$ \\
Cadmium & $0.110 \pm 0.003$ & $0.083 \pm 0.003$ & $0.081 \pm 0.00$ & $.0913 \pm 0.002$ \\
Nickel & $0.100 \pm 0.02$ & $0.05 \pm 0.000$ & $0.02 \pm 0.00$ & $0.056 \pm 0.001$ \\
Zinc & $0.101 \pm 0.003$ & $0.109 \pm 0.003$ & $0.106 \pm 0.003$ & $0.105 \pm 0.003$ \\
Mercury & $0.103 \pm 0.005$ & $0.474 \pm 0.006$ & $0.480 \pm 0.00$ & $0.352 \pm 0.036$ \\
Arsenic & $0.000 \pm 0.000$ & $0.000 \pm 0.000$ & $0.000 \pm 0.000$ & $0.00 \pm 0.000$
\end{tabular}

$\mathrm{RSU}=$ Rainy Season Upstream

RSM = Rainy Season Midstream

RSD $=$ Rainy Season Downstream

Table 3 Average Annual Heavy Metal Contents (Mg/Dm $\left.{ }^{3}\right)$

Legend:

\begin{tabular}{|c|c|c|c|}
\hline & RSA & DSA & AA \\
\hline Chromium & $0.580+0.000$ & $0.676+0.697$ & $0.628+0.034$ \\
\hline Lead & $0.345+0.006$ & $0.633+0.017$ & $0.489 \mp 0.011$ \\
\hline Copper & $0.049 \pm 0.023$ & $0.529+0.002$ & $0.154+0.002$ \\
\hline Cobalt & $0.109 \pm 0.002$ & $0.271 \pm 0.768$ & $0.192 \pm 0.039$ \\
\hline Vanadium & $0.150 \pm 0.003$ & $0.061 \overline{4} \pm 0.067$ & $0.141 \pm 0.035$ \\
\hline Iron & $11.94 \overline{7} \pm 0.095$ & $10.46 \pm 0.000$ & $8.704 \pm 0.048$ \\
\hline Manganese & $0.012+0.017$ & $0.099 \mp 0.000$ & $0.056 \pm 0.008$ \\
\hline Cadmium & $0.091+0.002$ & $0.068+0.001$ & $0.491 \mp 0.001$ \\
\hline Nickel & $0.056 \pm 0.00$ & $0.056 \pm 0.000$ & $0.056 \pm 0.000$ \\
\hline Zinc & $0.105 \overline{+} 0.003$ & $0.078 \overline{+} 0.000$ & $0.092 \mp 0.001$ \\
\hline Mercury & $0.352 \pm 0.004$ & $0.059 \pm 0.000$ & $0.206 \pm 0.002$ \\
\hline Arsenic & $0.000 \pm 0.000$ & $0.189 \pm 0.017$ & $0.095 \pm 0.008$ \\
\hline
\end{tabular}

RSA = Rainy Season Average 
$\mathrm{DSA}=$ Dry Season Average

$\mathrm{AA}=$ Annual Average

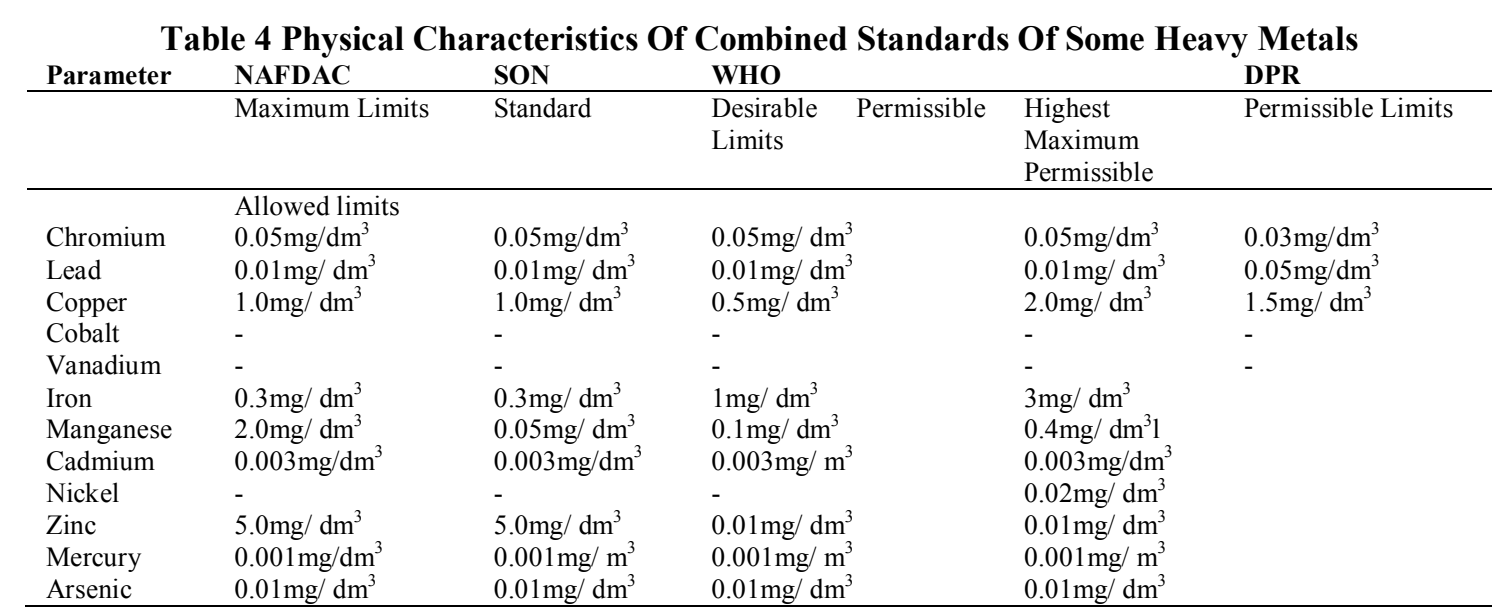

The results of the heavy metal concentrations of Aba River collected at the upstream, midstream and downstream in the two seasons, dry and rainy, were compared with those of drinking water standards of WHO (World Health Organization), SON (Standard Organization of Nigeria), DPR (Department of Petroleum Resources) and NAFDAC (National Agency for Food and Drug Administration and Control) permissible limits for water quality. Chromium was far higher in the water samples $\left(0.604+0.00 \mathrm{mg} / \mathrm{dm}^{3}\right.$ in the upstream, $0.614+$ $0.0 \mathrm{mg} / \mathrm{dm}^{3}$ in the midstream and $0.871+0.00$ in the downstream) when the WHO highest desirable was $0.05 \mathrm{mg} / \mathrm{dm}^{3}$ and the maximum permissible level was $0.05 \mathrm{mg} / \mathrm{dm}^{3}$. Chromium was therefore more than ten times higher than the maximum permissible level for drinking water rendering the Aba River unsuitable for drinking (Table 1, 2 and 3).

$\mathrm{Pb}$ was also far more in the samples than the standard. $\mathrm{Pb}$ concentration was $0.2600 \pm 0.005 \mathrm{mg} / \mathrm{dm}^{3}$ in the upstream, $0.376 \pm 0.513 \mathrm{mg} / \mathrm{dm}^{3}$ midstream and $0.406 \pm 0.00 \mathrm{mg} / \mathrm{dm}^{3}$ in the downstream in the rainy season though the dry season value was double that of rainy season because of concentration factors. The maximum permissible level for $\mathrm{Pb}$ by WHO was $0.01 \mathrm{mg} / \mathrm{dm}^{3}$, that is, about 20 times more in the rainy season and 40 times more in the dry season. Aba River was therefore highly polluted with $\mathrm{Pb}$. When particles of lead are airborne for a period of about ten days they fall to the ground and become distributed in soils and water sources including fresh surface water, salt water, well water and other drinking water bodies (12). High concentrations of lead cause irreversible brain damage (encephalopaty), coma and death if not treated immediately (13). Other symptoms of lead toxicity include gastrointestinal disturbance, abdominal pain, cramps, constipation, anorexia and weight loss, immunosuppressant effect and slight liver impairment (14). Copper was lower in the sample than in the standards. The level of copper does not portray any threat in the water sample.

Cobalt, vanadium and nickel had no desirable level from these three regulatory bodies so cannot be evaluated with them.

The concentration of iron was more in the samples than the standards, its concentration ranged from $5.00+00 \mathrm{mg} / \mathrm{dm}^{3}$ in the upstream, $5.40+0.00 \mathrm{mg} / \mathrm{dm}^{3}$ midstream and $6.00 \mathrm{mg} / \mathrm{dm}^{3}$ in the downstream in the dry season but double these values in rainy season perhaps, because of flood water. Concentration of manganese was less in the samples (in both seasons) than the levels given by the Regulatory bodies but Cd concentrations were far more in the samples. More Cd levels were seen in the rainy season than in the dry season. Zinc level was less in the samples. The level of zinc in the sample was $0.066+0.00 \mathrm{mg} / \mathrm{dm}^{3}$ in the dry season and $0.101 \pm$ $0.00 \mathrm{mg} / \mathrm{dm}^{3}$ in the rainy season since the maximum permissible level was $3.00 \mathrm{mg} / \mathrm{dm}^{3}$ by WHO and $5.00 \mathrm{mg} / \mathrm{dm}^{3}$ by the NAFDAC, SON and DPR. Aba River is therefore usable in terms of zinc concentration.

Mercury level was far more in the samples than the standard permissible level. The concentration of mercury was $0.045+0.00 \mathrm{mg} / \mathrm{dm}^{3}$ in the dry season and about 4 times more in the rainy. Dry season water samples exceeded the permissible $\mathrm{Hg}$ level by WHO. The high level of mercury may be attributed to the effluents from the cosmetic industries in Aba. Mercury exposure results in a variety of human ill health conditions. The degree of impairment and the clinical manifestations that accompany mercury exposure largely depend upon its chemical state and the route of exposure (15). High concentrations of mercury lead to reduced growth of plants and to kidney and liver failure (16). One hazardous effect of mercury in the aquatic environment is that it bio-accumulate in the food chain (17).

The level of arsenic in the dry season samples was far higher than those of the regulatory bodies even though arsenic was not detected in the rainy season. The high level of arsenic in the dry season may have resulted from the dust particles containing arsenic which are deposited in the water bodies (16). Chronic effects 
of arsenic intoxication are skin abnormalities (darkening of the skin and the appearances of small "corn" or "warts" on the palms and soles (18), lower birth weights of babies and abnormal percentage of male to female births are apparent suggestions that arsenic affects babies in the uterus (19).

In general the following heavy metals had their concentrations far above the maximum permissible level; lead, copper, iron, mercury, arsenic. These high concentrations indicate high pollution level of these metals in Aba River. The sources of these heavy metal pollution may be from the domestic and industrial liquid wastes and air particles which are deposited into the Aba River. Vehicular emissions are also washed down into the river, as well as refuse from dumpsites which are carried into the river by rain. The high concentrations of these heavy metals pose a lot of health risk to both aquatic and human lives.

Heavy metal pollution in Aba River varied with location as the values of most of the metals were higher in the downstream than the upstream as a result of water flowing downwards carrying particles. Heavy metal concentration in water also varied with seasons.

The results obtained in this study showed that the concentrations of most of the heavy metals in Aba River were above the standards of the Regulatory bodies, indicating a high level of pollution of Aba River. The issue of heavy metal contamination should therefore be given high priority by Environmental and Government Departmental Agencies.

\section{References}

[1]. G. A. Obodo (2009). Food, Water and Land Pollution and Analysis Supreme Publishers, Owerri, Nigeria pp1-4

[2]. M. Harada (1994). Environmental Contamination and Human Rights Case of Minamata Disease "Ind. Environ. Crisis and Quality" 8:141-154.

[3]. T. A. Roberts (1999). Heavy Metal Toxicity, www.emedicine.com Toxicity pp 4-5

[4]. F. R. Benn and C. A Mcauliffe (1975). Chemistry and Pollution. The Ann Press Limited London pp 19-102.

[5]. T. Waldron (1989). Diet and Crafts in Towns. Bar. Oxford, Ap. 55

[6]. T. Lister and J. Renshaw (1991). Understanding Chemistry for Advance Level lot Edition. John Wiley and Sons, New York pp 241250 .

[7]. R. M Harrison (1990). Pollution Causes Effects and Control. Royal Society of Chemistry, London, pp 297-307.

[8]. Wikipedia the Free Encyclopedia (2008). www.wikipedia.com

[9]. A. K, Koli, W. R. Williams E. B, Meday, E.E Wriglu, T. M Burrel (1991). Mercury Levels in Fresh Water Fish of the State of South Carolina Bull Environ. Contam. Toxico 17 (1) pp 82-85.

[10]. A A. Adeniyi, J. Fashola and O. A. Ekanem (1993). Comparative Evaluation of Heavy Metals in Lagos Dumpsites, Niger Rev Sc. Pp 65-69.

[11]. S. O Adefemi, S. S. Asaolu, and O. Olaofe (2007). Majpr Elements in Fish (Illisha Africana), Sediments and Water from Selected Dams in Ekiti State Research Journal of Environmental Sciences ISSN Pp 1819-3412.

[12]. J. W. Hill (1980). Chemistry for Changing Times. Third Edition Copyright by Burgress Publishing Company Pp 258-366

[13]. United States Environmental Protection Agency (1996). Environmental Quality. Washington D. C. USA Pp 253.

[14]. United States Environmental Protection Agency (1999). http//www epa//ttnuatd(hiter/lead/html.

[15]. Oral Chelation (2005). Oral Chelation for Heavymetals Defoxification Extreme Health Us Inc 16.

[16]. M. N. Mgbemena and V. I. Onwukeme (2012). Metal in Dust from Aba, Abia State Nigeria, Using Car Windscreen as an Inert Passive Collector. Journal of Applied Chemistry Volume 3, Issue 1 pp 53-66.

[17]. Morton (1976). Water Pollution, Causes Mirmir Publishers Inc Worzally Publishing Co USA Pp 21.

[18]. United States Environmental Protection Agency (1984). Environmental Quality. Washington D.C. USA.

[19]. Nord (1988). Nord Guidelines for Integrated Monitoring in the Nordic Countries Nordic Council of Ministers Lopenhages, Environmental Report 1:26. 